\title{
Special thanks to reviewers for 2020: the COVID-19 year of trial by fire
}

\author{
Elena N. Naumova ${ }^{1}$
}

Accepted: 3 April 2021 / Published online: 3 May 2021

(c) The Author(s), under exclusive licence to Springer Nature Limited 2021

For so many of us, it was difficult and challenging year with the high toll of the pandemic on human lives, health, wellbeing, economic losses and lost opportunities. Yet, we have also learned creative ways from each other to build and sustain compassion, endurance, resilience, and support. During the worldwide lockdowns many of our readers have had to master new work from home environments and remote communication strategies. Likewise, we have mastered zoom-meetings across continents with the editorial, management, typesetters, and production teams in UK, US, Germany, and India.

Late February of 2020, right before the WHO declared the pandemic, the Journal of Public Health Policy (JPHP) switched to a new manuscript management system supported by Springer Nature Publishing. This system offers better functionality, tracking, and sharing with our readers, reviewers, and the members of Editorial Board. We tackled this transition with the help of Jessica Torr, Meghan Hartwick, and Katherine Chabalko, while Phyllis Freeman was wrapping up the submissions received via the old system.

In 2020, we received $\mathbf{5 7 0}$ submissions from more than $\mathbf{7 2}$ countries. We received ten or more submissions from the contributors residing in United States of America (119), China (69), India (62), the United Kingdom (26), Turkey (20), Iran (19), Australia (14), Pakistan (14), Japan (13), Korea (South) (13), Spain (11), Italy (10) and Bangladesh (10). Authors from Algeria, Austria, Bosnia-Herzegovina, Brazil, Canada, Colombia, Croatia, Cyprus, Denmark, France, Germany, Ghana, Greece, Grenada, Indonesia, Ireland, Israel, Jordan, Kenya, Malaysia, Mexico, Nepal, Nigeria, Palestine, Peru, Philippines, Portugal, Poland, Saudi Arabia, Serbia, South Africa, Switzerland, Taiwan, Thailand, Tunisia, United Arab Emirates, and Vietnam who contributed three or more manuscripts (see Fig. 1).

As the venue for public health professionals, we felt the impact of the pandemic on the content and focus of submissions to the Journal this year. In March of 2020 we set up the Topical Collection on Public Health Response to COVID-19 and as

Elena N. Naumova

elena.naumova@tufts.edu

1 Friedman School of Nutrition Science and Policy, Tufts University, Boston, USA 


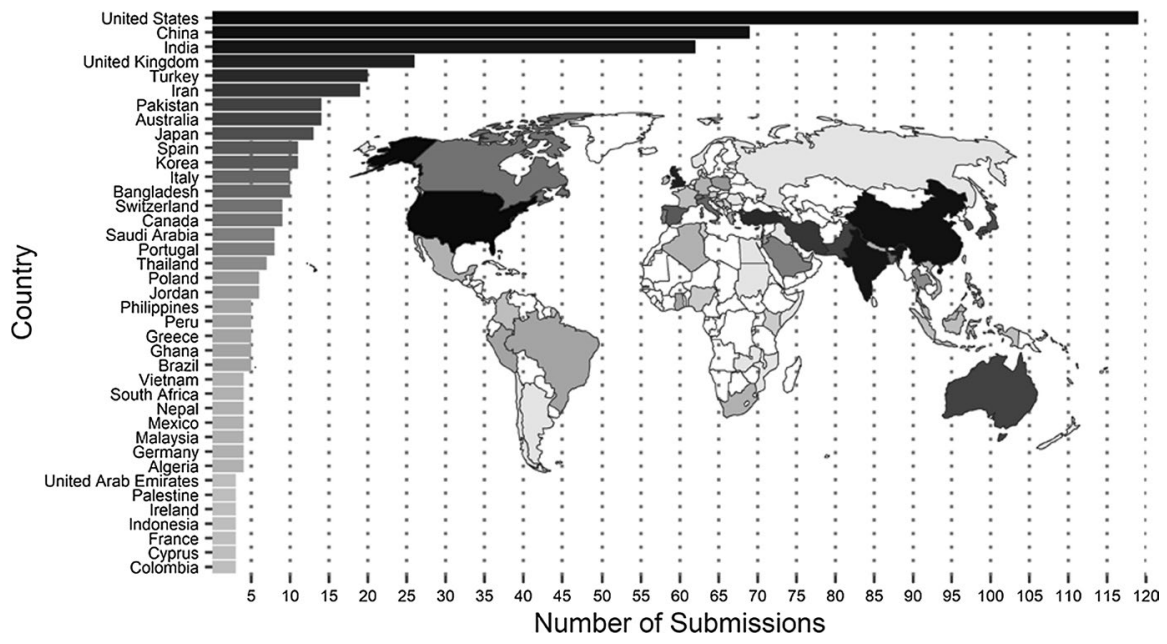

Fig. 1 JPHP received three or more manuscripts from 40 countries in 2020

of 25 March 2021 we have published 15 original articles, Viewpoints, and Letters to the Editors highlighting the challenges, recommendations, and achievements of public health professionals. As expected, many our contributors and reviewers experienced the pressure of being on the frontline and we are immensely thankful for their committed time and dedication.

We thank the constructive guidance and timeliness provided by 145 reviewers who completed 195 reviews over the past year. Our reviewers' pool represents five continents and includes 26 countries: Australia, Canada, Ecuador, France, India, Indonesia, Iran, Italy, Japan, Kenya, South Korea, Lebanon, Nepal, The Netherland, New Zealand, Pakistan, Peru, Russia, Saudi Arabia, Spain, Sweden, Switzerland, Taiwan, Trinidad and Tobago, United Kingdom, and USA. We would like to express our gratitude to: 


\begin{tabular}{|c|c|c|}
\hline Naglaa El Abbadi & Barbara Haesler & Elize Massard da Fonseca \\
\hline Muhammad A J Adnan & Meghan Hartwick & Stephen A. McCurdy \\
\hline Andrea Acevedo & Furqan Hashmi & Elly Mertens \\
\hline Mark A Gottlieb & James Hawdon & Joel Mintz \\
\hline Mehdi Ahmadi & Marie Hayes & Alicia Monroe \\
\hline Chiara Altare & Patrick Hemming & Robert D. Morris \\
\hline Oyedolapo Anyanwu & Erin Hennessy & Carles Muntaner \\
\hline Francisco Armada & Eve J. Higginbotham & Emil Nasritdinov \\
\hline Shelly Arora & Ellen T. Hoen & Poonam Nayar \\
\hline Glory O. Atilola & Aida Hoteit & Keith Neal \\
\hline Dhan Bahadur Shrestha & Jayne Hutchinson & Jesus Andree Neyra Leon \\
\hline Naheed Banu & Kenneth Kalu & Mohamed O. Nour \\
\hline Fran Baum & Anita Kar & Rosalie Pacula \\
\hline Ryan Benner Simpson & Laura G. Kehoe & Sukri Palutturi \\
\hline Debanjan Bhattacharya & Osnat Keidar & Apurva Kumar Pandya \\
\hline Leslie I. Boden & Elizabeth King & Lidia Panico \\
\hline Lee Breckenridge & Janni Kinsler & Ganeshkumar Parasuraman \\
\hline James Chauvin & Deborah Kochevar & Kee Park \\
\hline Jamie Chriqui & Patrick Marius Koga & Parveen Parmar \\
\hline Alessandro Colombo & Lloyd J. Kolbe & Wendy Parmet \\
\hline Laura Corlin & Karen Kosinski & Enrico Pavignani \\
\hline Ron Crump & Alexandra Kulinkina & Farrukh Qureshi \\
\hline Tess Boley Cruz & Dolly Kumari & Rayan Jo Rachwan \\
\hline Adolfo Cuevas & Shyama Kuruvilla & Chris Rees \\
\hline Ghassan Daher & Irina Kuznetsova & Aaron Reeves \\
\hline Andrew Day & Ana Langer & Thomas Ricketts \\
\hline Richard A. Daynard & Breanne Langlois & Judit Rius Sanjuan \\
\hline Loren De Freitas & Breanne K. Langlois & Robin Robinson \\
\hline Akira Ehara & Gideon Lasco & Beth Rosenberg \\
\hline Ahmed Elsharkawy & David Legge & Oliver Rubin \\
\hline Elizabeth Erdman & Rago Lembit & Indranil Saha \\
\hline Luis Eugenio Portela & Peter Levine & Rajiv Sarkar \\
\hline Fernandes de Souza & Xiuting Li & Stephen Schoenbaum \\
\hline Ramón Feenstra & Lawrence Liberti & Jodi Segal \\
\hline María Fernanda Vinueza-Veloz & Gitanjali Singh & Fernando Sempértegui \\
\hline Erin Fredericks & Michael Sinha & Rajib Shaw \\
\hline Phyllis Freeman & Yei-Whei Lin & Changwoo Shon \\
\hline María Teresa García-Nieto & Martha Livingston & Nothemba Simelala \\
\hline Aythamy Gonzalez-Darias & Eric Lofgren & Steven Stack \\
\hline Julie Rowlet & Marian MacDorman & Thomas J Stopka \\
\hline Subrata Roy & Nithin Manchery & Alison Talbert \\
\hline Indrajit Gowdar & Gerald Markowitz & Bikash Bikram Thapa \\
\hline Michelle Grant & Anastasia Marshak & Alex van den Heever \\
\hline & & Susan Van Katwyk \\
\hline
\end{tabular}




$\begin{array}{ll}\text { Maria F. Vinueza-Veloz } & \text { Cassandra White } \\ \text { Marianne Vyas } & \text { Roy Widdus } \\ \text { Deborah K. Walker } & \text { Norbert L. W. Wilson } \\ \text { Mary White } & \text { John Wooding } \\ & \text { Yiqing Xu }\end{array}$

\author{
Danyuo Yiporo \\ Helen Young \\ Ngoyi Zacharie Bukonda \\ Jonathan Zenilman \\ Bingjie Zhou
}

My first year as Editor-in-Chief has taught me valuable lessons-to treasure the resilience and wisdom of my colleagues, to nurture talents and to remain optimistic. I was moved and impressed by the reviewers' thoughtfulness and authors' responsiveness to comments and suggestions, by the enthusiasm of investigators and practitioners starting their career, and perseverance of scientists for whom this pandemic was just the next on the list. The submissions of this year touched a broad range of topics that will be relevant for generations to come. Among many are: climate change and health equity, vaccination hesitancy, health of refugees and migrant workers, misinformation and health communication, microbial resistance, domestic violence and opioid surge. In times of crises, the deficiencies of systems that disfavor or threaten people exploited for a long list of reasons, including social status, religious beliefs, native tongue, skin color, or sexual orientation reveals persistent structural inequalities. These inequalities have deep historical roots. Each act of injustice, violence, economic deprivation, or environmental degradation toward one sown the seeds of future inequality for many. I will keep the Journal attuned to the voices of those who seek solutions, offer suggestions, try and fail and try and succeed. It is my continued hope that despite the challenges of a given day "In all things of nature there is something of the marvelous" (as attributed to Aristotle).

Elena N. Naumova, Editor-in-Chief

Publisher's Note Springer Nature remains neutral with regard to jurisdictional claims in published maps and institutional affiliations. 